\title{
Drugs, Violence and Trauma in the Colombian Context: A Health Care Point of View of a Human Rights Challenge
}

\author{
${ }^{1}$ Andres M Rubiano, ${ }^{2}$ Jorge HM Muñoz, ${ }^{3}$ Glyn Estebanez, ${ }^{4}$ Alvaro I Sanchez, ${ }^{5}$ Juan C Jacob Puyana, ${ }^{6}$ Juan C Puyana
}

\begin{abstract}
The impact of violence due to illicit drugs markets varies tremendously in magnitude and characteristics depending on several factors. In Colombia, drugs and trauma are related in multiple ways. From interpersonal violence at the street level to the criminal actions of various armed groups whose violent campaigns are financed through the vast profits associated with the illicit drug market. The objective of this review is to analyze the association of the illicit drugs trade and its impact on violence in Colombia from the viewpoint of healthcare providers who care for trauma patients. Injuries related to drug traffic violence are high in Colombia, and only a small reduction was obtained after severe crime enforcement policies. The societal cost of the war on drugs policy is high on trauma deaths and related disabilities according to several reports from non-government agencies and the Colombian National Institute of Legal Medicine and Forensic Sciences. A health care initiative in order to understand the drug phenomena as a health care problem shifting the actual criminal-justice based on the approach can minimize the human rights crisis that is evolving being faced every day at health care facilities in Colombia. This new approach in the actual post-conflict environment deserves to be analyzed.
\end{abstract}

Keywords: Colombia, Drug Trafficking, Injury, Trauma, Violence

How to cite this article: Rubiano AM, Muñoz JHM, Estebanez G, Sanchez AI, Puyana JCJ, Puyana JC. Drugs, Violence and Trauma in the Colombian Context: A Health Care Point of View of a Human Rights Challenge. Panam J Trauma Crit Care Emerg Surg 2018;7(2):158-163.

\footnotetext{
${ }^{1}$ Professor of Neurosurgery/Medical Director, ${ }^{2}$ Medical Doctor, ${ }^{3,4}$ General Surgeon ${ }^{5}$ Medical Student, ${ }^{6}$ Professor of Surgery and Critical Care.

${ }^{1}$ Neurosurgery/Clinical Research, El Bosque University/ MEDITECH Foundation, Bogotá, Cundinamarca, Colombia

${ }^{2}$ Clinical Researcher, MEDITECH Foundation, Neiva, Huila, Colombia

${ }^{3}$ General Surgery, North Hamshire Hospital, Hamshire, Basingstoke, UK

${ }^{4}$ Surgery, Universidad del Valle, Cali, Valle, Colombia

${ }^{5}$ School of Medicine, Virginia University, Charlotsville, Virginia, USA

${ }^{6}$ Department of Surgery, University of Pittsburgh, Pittsburgh, Pennsylvania, USA
}

Corresponding Author: Andres M Rubiano, Professor of Neurosurgery/Medical Director, El Bosque University/ MEDITECH Foundation, Bogotá, Cundinamarca, Colombia, Phone: 573006154775, e-mail: andresrubiano@aol.com

\section{Source of support: Nil}

Conflict of interest: None

\section{INTRODUCTION}

The cultivation, use, and trade of psychoactive and other drugs have existed since the time of ancient civilizations. Illegal drug trafficking is a global black market consisting of the cultivation, manufacture, distribution, and sale of these illicit goods. Drugs and trauma are related in multiple ways in Colombia. From interpersonal violence at the street level to the criminal actions of various armed groups whose violent campaigns are financed through the vast profits associated with the illicit drug market. The impact of illicit drug markets on the occurrence and the magnitude of violence in Colombia varies tremendously depending on many factors. nonmedical use of psychoactive drugs are inevitable and its presence in society is an important cause of social and individual harm. nonmedical psychoactive drug use is a disease and as such would be more successfully confronted by the introduction of worldwide drug control intervention policies, emanating from a public health perspective rather than continuing with the already lost war on drugs. The objective of this review is to analyze the association of illicit drugs and its impact on violence in Colombia, from the viewpoint of health care providers that face day to day basis the societal cost of this human rights challenge.

\section{The Drug Trade and Drug War History}

The prohibition of alcohol consumption under Islamic law is mentioned in the "Koran" in the 7th century. Hashish was prohibited in Egypt in the 11th and 12th centuries. In the 14th century, certain Islamic areas became tolerant of cannabis use for medical purposes, subsequently leading Pope Innocent VIII to ban the use of cannabis and support the Spanish Inquisition against the Arabs. ${ }^{1-3}$ The Inquisition also proceeded into Central and South America, where "sacred" plants of the Mesoamerican cultures were prohibited as works of the devil. In Northern Europe, Protestants were also responsible for passing drug laws motivated by religious intolerance. In 1516 a "Bavarian Purity Law", was a reflection of Protestant irritation about 'alcohol' production by some monastic's groups of the Catholic 
Church. ${ }^{1-3}$ Coffee, regarded as a Muslim drink, was prohibited to Christians in its native Ethiopia until as late as 1889. The introduction of coffee in Europe from Muslim Turkey prompted called for it to be banned. Pope Clement VIII sanctioned its use in 1600. The early association of coffee with rebellious political activities led to its banning in England, among other places. ${ }^{1-3}$ In late imperial China, opium imported by the British East India Company was widely consumed by all social classes in the south of the country. ${ }^{4}$ Between 1821 and 1837 imports of the drug increased fivefold. The chinese government attempted to end this trade, and their efforts were initially successful, destroying the British opium stock in May 1839. However, to protect this lucrative trade, the British declared war on China and as a result of this "First Opium War", the United Kingdom forced China to permit British merchants to trade opium with the general Chinese population. ${ }^{4}$ During the 19 th century, one of the most important reasons for the increase in opiate consumption was the prescribing and dispensing of legal opiates by physicians and pharmacists. ${ }^{2,4-6}$ In the early 1900s, the use of cocaine and other drugs continued to gain popularity, culminating in the introduction of prohibition. Irrespective of the knowledge of the illegality of their actions, drug use amongst young people continued to rise and subsequently governments' efforts to enforce their prohibitory stance were strengthened in many countries from the 1960s onwards. This toughened government position resulted in the creation of a new form of the drug trade that incorporated the utilization of modern illicit methods. These included the purchase and financing of legitimate businesses to provide cover for illegal operations, the use of sophisticated electronic tracking devices, airplanes, fast boats and other elaborate transportation schemes, and importantly the use of heavily armed groups to protect this illicit trade. The distribution networks for these illegal drugs also became highly elaborate and grew to involve vast numbers of people at an international level in the production, preparation, trading and consumption stages. Prohibition of psychoactive drugs formed the foundation of many international policies of countries, so much so that often their support for foreign governments was dependent upon the adherence of such policies. ${ }^{2,6,7}$ This multi-national campaign of prohibition instigated the modern "war on drugs", and as such marked in history the start of a period of increased violence related trauma that still persists today.

\section{Colombia's Violence Context on the Drug Trade and War}

The indigenous people of South America have cultivated Coca for centuries and historically the plant has played various roles in religious and social ceremonies of the Andean indigenous civilizations. The name initially was given to the plant by the Indians of Bolivia means "food for workers and travelers" and stemmed from the ability of chewed leaves to improve blood oxygen circulation and thus counter the hypoxemic effects of the high Andean altitudes in Colombia, Ecuador, Peru and Bolivia. ${ }^{8,9}$

Details of the early stages of drug trafficking in Colombia is unclear however it is believed that it was related to the migration of illegal drug production plants from Chile. By the early 1970s, Chile was an important regional center for cocaine processing. The problem became so relevant in Chile that it culminated in the introduction of the country's first antinarcotics law by Allende's government in 1973. Later that year the Chilean military formed a special narcotics unit, which posed such a significant threat to the drug, which traffickers opted to move drug production to other neighboring countries like Colombia and Peru. Subsequently groups of Colombians were educated in the techniques of transforming the plant into the illicit powder, thus laying the foundations of drug trafficking in Colombia.,10-12 The development of illicit production in Colombia helped perpetuate an already present state of social violence and this synergistic relationship established a lethal and terrifying situation that continues today. ${ }^{13}$

Violence in Colombia can be traced back to April 1948, when riots erupted in Bogota, in response to the assassination of a popular politician, the riots spread to the countryside and lasted for a more than a decade. This social uprising was only partially controlled and in the early 1960s, armed groups formed by rural citizens turned up, fighting against the social violence generated by armed political groups in rural areas. These groups were largely nationalistic and began developing links with international centers of communist affiliation, a common phenomenon across Latin America during that decade. ${ }^{10,13-15}$ However, after several years, these groups were confronted with the dilemma of either finding alternative ways of economic support to continue fighting or allow themselves to be part of the formal political system. In Colombia, the Revolutionary Armed Forces of Colombia (FARC), the National Liberation Army (ELN) and the People's Liberation Army (EPL) chose to finance their war efforts by taxing and protecting coca and opium related process, including production, processing, and distribution facilities as well by criminal activities such as kidnapping and extortion. Within this panorama, the 1970s were a starting era for the black market drug business, with the consolidation of the three main Colombian cartels (Cali, Medellin and Valle's North) rapidly growing in size, power and wealth through the use of increasingly ruthless and violent tactics. ${ }^{10,14}$ 
After establishing their dominance on the South American side of the market, in 1978 and 1979 the Colombian drug cartels began to successfully increase their control of wholesale distribution within the United States. However, with the initiation of the "war on drugs" strategy in the $1980 \mathrm{~s}^{9,11,12,16,17}$ and the successful anticartel operations (with the assistance of US law enforcement and intelligence agencies) during the "Plan Colombia" era in the 1990s, the cartels were forced to decentralize their production and distribution capabilities. Most of these fragmented cartels had to look elsewhere for protection, paying unprecedented amounts of money to the FARC, ELN, and to a new player: the auto defenses group (AUC) an ultra right-wing armed group formed by rich rural land-owners and also drug lords to protect themselves from FARC and ELN attacks. All of these armed groups were anxious to provide these services since they needed money to finance the weapon`s purchase and also the recruitment of new members to maintain the internal war. With this new strategic and tactical alliance, FARC, ELN and AUC groups were able to derive significant revenues from the protection and taxing of coca plantations. As the FARC and AUC began their own direct involvement in the production and distribution of drugs to the main consumer countries, they began to increase income exponentially and fueling their violent campaigns against military operations from the governments. ${ }^{3,18,19}$

The majority of Colombia's Cocoa leaves are cultivated on large plantations in southern and western and central jungle regions where coca farmers have destroyed nearly 2.4 million hectares of tropical forests to increase the areas available for coca plantations. Although the use of aerial and manual eradication programs (that take place at an extremely high ecological cost for Colombian's environment) have reduced the cultivated areas that yield coca harvests, the use of sophisticated agricultural technology, by coca farmers, has enabled them to enhance harvest production, thus limiting the impact of government and international-led interventions. Poor peasants are recruited to work the land and harvest illicit crops as their major source of income and in other cases, armed groups force farmers to pick coca fields. Harvested coca leaves undergo a complex transformation in clandestine processing laboratories to become the powder that is then exported. At each step of the process, significant quantities of various toxic chemicals are used and dumped, causing serious detriment to the environment and people. $3,9,14,17$ Once the narcotic production process is complete, high quantities of drugs are smuggled to Central America and several Caribbean countries through the use of airplanes, fishing vessels, commercial cargo ships, homemade submarines and stealthier speedboats. The US authorities estimate that approximately $70 \%$ of cocaine leaves Colombia via the Pacific, $20 \%$ via the Atlantic and $10 \%$ via the Bolivarian Republic of Venezuela and the Caribbean. ${ }^{20}$ The illicit cargo, often hidden in secret compartments and containers built into ships is unloaded at the various port destinations and the majority is then transported onwards to the US mainland (primarily via the Mexico-US border) or Africa and then subsequently to Europe. ${ }^{9,10,18-22}$

\section{Drug-Associated Violence and Injuries in Colombia}

An emergency room admission and drug use study was conducted in a public hospital in 1992 during the climax of the drug violence era in Medellin (COL). $42 \%$ of the trauma patients were admitted with positive alcohol in blood and $20 \%$ with cocaine metabolites in urine samples. ${ }^{23}$ In 1997, the same center repeated the study and found that $37 \%$ of the patients were positive for alcohol and $10 \%$ were positive for cocaine. In 2004 , a sample of 1,066 ( $50 \%$ trauma and 50\% medical) patients presenting at two busy emergency rooms (one private and one public) in Bogota were tested for drugs and alcohol. $14.4 \%$ of the patients were positive for alcohol and drugs; of these, $2 \%$ were positive for cannabinoids, and $1 \%$ was positive for cocaine in urine samples. ${ }^{23}$ These findings correlate well with those of a recent study conducted in Cali that found that $2.6 \%$ of patients, in a cohort that included minors admitted with traumatic injuries tested positive for illicit drugs. The authors also concluded that the use of illicit drugs appeared to be associated with higher levels of interpersonal violence. ${ }^{24}$

According to the National Institute of Legal Medicine and Forensic Science, the homicide rate in Colombia has decreased 10 to $15 \%$. Prior to 2002, the annual number of violent deaths was greater than 50,000 and $60-70 \%$ of these deaths were as a result of interpersonal violence related to narcotics and the actions of guerillas and paramilitary groups. At 2013, homicides constitute $53.6 \%$ of total violent death $\mathrm{s}^{25}$ with the remaining half including suicides, work-related deaths, motor vehicle accidents, and poisonings. In 2002, 215-243 nonfatal injuries occurred and $50 \%$ were related to interpersonal violence. This was the year homicide rates begin to decline (Table 1 ). In 2013, 302, 484 nonfatal injuries occurred and 52.5\% were related to interpersonal violence. ${ }^{25}$ Thus, while the homicide rate of the country may be declining, it is apparent that illicit drug trade-related trauma still poses a significant public health challenge in Colombia. (Table 2 and Fig. 1). 
Table 1: Intentional homicides in Colombia (per 100,000 people). Source: World Bank Statistics

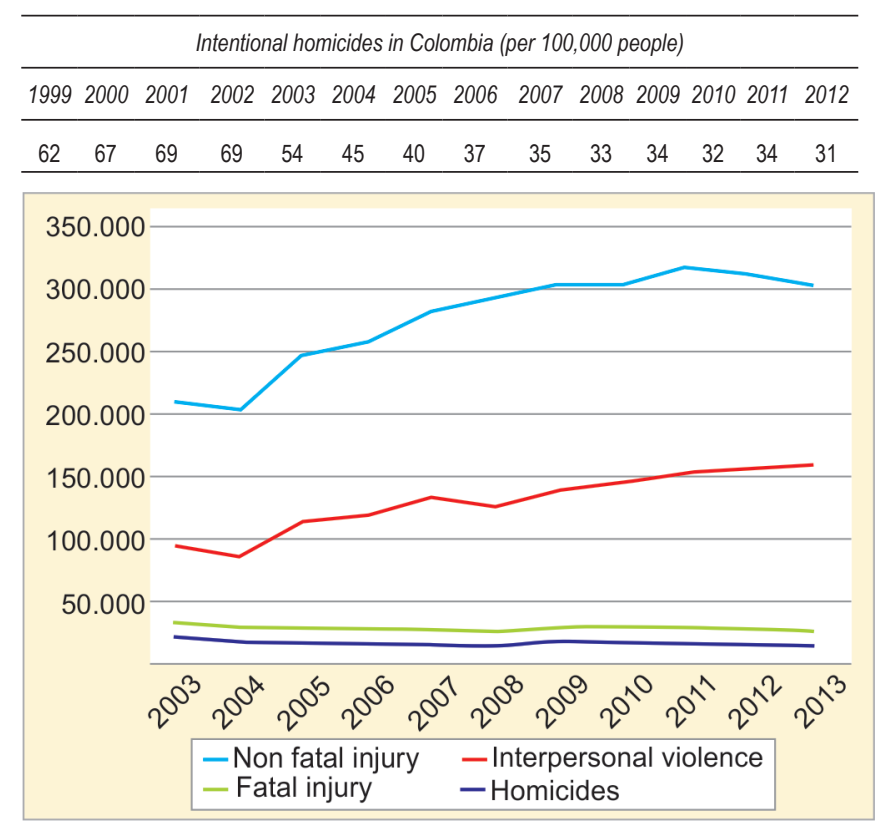

Fig. 1 : Trend of nonfatal injuries and fatal injuries in Colombia. Source: Colombian National Institute of Legal Medicine)

\section{War on Drugs Policy in Colombia}

The goal of the Colombia Plan, one of the earliest programs specifically dedicated to support Latin American countries in the war on drugs, was to stem the nearly $\$ 40$ billion-a-year flow of cocaine to the United States, the majority of which was coming from Colombia. In the aftermath of $9 / 11$, the global war on terrorism, the US and Colombian government declared Colombian armed groups involved in drug traffic "terrorists with a global reach" and stated that they posed a threat to US interests. What had been strictly an anti-drug campaign was thus, by a deft use of the terrorism trump card, transformed into a counterinsurgency campaign.

Unfortunately, nothing is straightforward with regards to cocaine in Colombia, and the process of eradicating or even slowing cocaine production (something at the heart of Plan Colombia) was a formidable task. Today, almost $42 \%$ of Colombia's rural population falls beneath the poverty line. Approximately $12 \%$ of the Colombian population earns less than \$2 USD a day and 5.6\% live with a daily income of less than $\$ 1,25$ USD. For a citizen living in such conditions, coca farming is an obvious option and often serves as the only realistic route of improving the lives of themselves and their families. Coca cultivation in Colombia is fueled by the vast levels of poverty that exist in the country, thus it is extremely unlikely that cessation of illicit drug, production will occur in the absence of any realistic alternative programs that address the prevalent social inequalities. The substantial profits accrued from the illicit cocaine market in the US are unevenly divided between recipients at the various levels of the trafficking process (Fig. 2). The largest profits are generated between the US wholesale level and the consumer, with Andean farmers receiving only $1.5 \%$ of the profits, according to a 2010 UN report. ${ }^{26}$

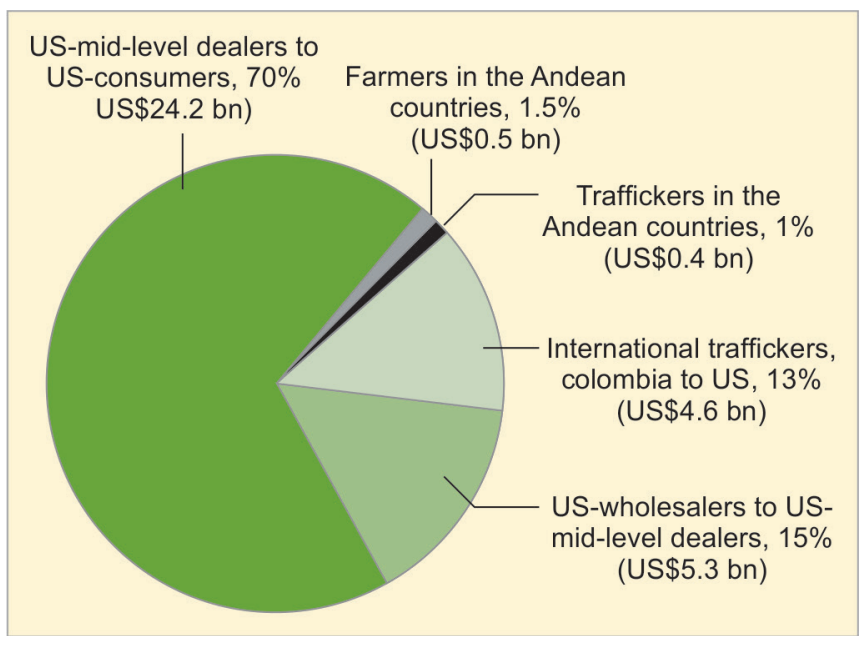

Fig. 2: Distribution of gross profits in percentage of the US\$35 billion US cocaine market from 2008. Source: UNODC. The Globalization of Crime: A Translational Organized Crime Threat Assessment. Vienna S: United Nations Office on Drugs and Crime, 2010.

The amount of money earned by drug traffickers from the lucrative markets of drugs in Europe and USA are transferred to banks in Colombia, Mexico or to various fiscal paradises throughout the world. In 1994 Mexican trafficker profits were estimated to be in the region of $\$ 30$ billion, four times greater than the country's oil revenue the same year, and $7.1 \%$ of the countries gross net product. In 1995, the US Secretary of the Treasury calculated that the world's money laundering was between $\$ 300$ and $\$ 600$ billion a year, with a figure in the USA, estimated as being $\$ 100$ billion from drug trafficking alone. Figures

Table 2. Trend of non-fatal injuries and fatal injuries in Colombia. Source: Colombian National Institute of Legal Medicine

\begin{tabular}{llllllllllll}
\multicolumn{10}{c}{ Trend of nonfatal injuries and fatal injuries in colombia } \\
\hline & 2003 & 2004 & 2005 & 2006 & 2007 & 2008 & 2009 & 2010 & 2011 & 2012 & 2013 \\
\hline Non faltal injury & 210.168 & 203.438 & 247.567 & 258.256 & 282.457 & 292.869 & 303.471 & 304.252 & 316.864 & 311.514 & 302.484 \\
Interpersonal & & & & & & & & & & & \\
Violence & 93.850 & 86.478 & 114.323 & 119.099 & 133.475 & 126.869 & 138.617 & 145.184 & 152.865 & 155.507 & 158.798 \\
Fatal injury & 33.206 & 29.724 & 28.461 & 27.574 & 27.920 & 26.958 & 29.433 & 29.922 & 28.996 & 28.496 & 26.623 \\
Homicides & 22.199 & 18.888 & 17.331 & 16.274 & 16.318 & 15.250 & 17.717 & 17.459 & 16.554 & 15.727 & 14.294 \\
\hline
\end{tabular}


from the USA authorities suggested that there was \$8-30 billion of laundered money circulating in Mexican banks in 1996 alone. $^{27}$

\section{Violence and Trauma-Related to Drug Traffic}

The relationship between drugs, violence, and trauma is complex and multifaceted and appears to exist on three levels: a result of the direct psychopharmacological effect, violence carried out by the drug-taking population for economic reasons and violence in of all stages in the world of illicit drug trafficking. Within these urban and rural areas, injuries are common with the most frequently sustained injuries a result of bullets, as well as from sharp or bladed objects which are often placed within explosives. Firearms are the most widely documented instrument used in the conflict with the most common types of weapons being assault rifles and grenade launchers. Traumatic brain injuries and extremities injuries are seen on a day-by-day basis in busy health care centers in rural and urban Colombia. Some of the victims of this intense conflict in countries like Colombia are members of the army and police who are frequently wounded or even killed in action, however traumatic injuries to civilians, within these areas are also common. Despite the efforts of the numerous trauma MEDEVAC teams to provide adequate trauma care for the injured within these hostile environments, this issue adds significant stress on the countries with already struggling health care systems.27,28

\section{CONCLUSION}

The "war on drugs" continues to be a human rights challenge, with immeasurable cost of lives lost and disabilities associated to the violence generated by these activities. The vast profits accrued by organizations involved in drug trafficking fuel crime, violence, and corruption, and contribute to the destabilization of countries such as Colombia. The spectrum of drug-related injuries and violent trauma are spread along many communities in Colombia. The impact of these injuries affects families and society. A health care initiative categorizing the drug phenomena as a health care problem rather than the current criminal justice-based approach can minimize the human rights crisis that is evolving. The recent peace talks initiative opens an important opportunity to discuss these arguments at a nationwide level.

\section{ACKNOWLEDGMENTS}

The authors want to acknowledge the support of the MEDITECH Foundation research group and the work of the students of the Public Health, Social Development and Human Rights research group of South Colombian University in Neiva (Colombia).

\section{REFERENCES}

1. Matthee R. The Pursuit of Pleasure: Drugs and Stimulants in Iranian History, 1500-1900. 1st edition. Princeton NJ: Princeton University Press; 2005

2. Cohen P. Re-thinking drug control policy: Historical perspectives and conceptual tools. Geneva: Nations Research Institute for Social Development (UNRISD); 1993

3. Chepesiuk R. The War on Drugs. Santa Barbara, CA: An International Encyclopedia. 1st edition: ABC-CLIO; 1999

4. Dikötter F, Laamann L, and Xun Z. Narcotic Culture: A History of Drugs in China. 1st edition. Chicago: University of Chicago Press; 2004

5. Degrandpre R. The Cult of Pharmacology: How America Became the World's Most Troubled Drug Culture. Durham: Duke University Press; 2006

6. Webster P. Learning from history: a review of David BewleyTaylor's The United States and International Drug Control, 1909-1997. Int J Drug Policy 2003;14(4):343-346.

7. Levine H. Global drug prohibition: its uses and crises. Int J Drug Policy 2003;14(2):145-153.

8. UNODC. Coca Cultivation in the Andean Region: A Survey of Bolivia, Colombia, and Peru. Vienna A: United Nations Office on Drugs and Crime; 2006

9. ICG. War and drugs in Colombia: Latin American Report. Belgium: International Crisis Group; 2007

10. Hylton F. Evil Hour in Colombia. 1st edition. London: Verso; 2006

11. Miller R. Drug Warriors and Their Prey. United States: Praeger; 1996

12. Canby P. Latin America's Longest War. United States: The Nation; 2004

13. Aguirre K, Muggah R, Restrepo J and Spagat M. Colombia's hydra: the many faces of gun violence: Small arms survey. Oxford, Geneva: Conflict Analysis Resources Center (CERAC); 2006

14. Thoumi F. Why the Illegal Psychoactive Drugs Industry Grew in Colombia Journal of Interamerican Studies and World Affairs. Why the Illegal Psychoactive Drugs Industry Grew in Colombia. J Inter-Am Stud World Aff 1992;34(3):37-63.

15. UNODC. Colombian Survey. Vienna A: United Nations Office on Drugs and Crime; 2005

16. Bertram E. Drug War Politics: The Price of Denial. 1st edition. California: University of California Press; 1996

17. Buscaglia E and Ratliff W. Essays in public policy: War and Lack of Governance in Colombia: Narcos, Guerrillas, and U.S. Policy. California: Hoover Institution, Stanford University; 2009

18. Evans M. War in Colombia, Guerrillas, Drugs, and Human Rights in U.S.-Colombia Policy, 1988-2002. Colombian Documentation Project. Washington: George Washington University, National Security Archive Electronic Briefing; 2002

19. Graham B, Scowcroft B and Shifter M. Toward Greater Peace and Security in Colombia: Forging a Constructive U.S. Policy: Council on Foreign Relations, Inter-American Dialogue; 2000

20. NDIC. National Drug Threat Assessment 2009. United States: National Drug Intelligence Center; 2009

21. Horn M. DEA Congressional Testimony, Office of International Operations Drug Enforcement Administration: 
Regarding: Violent Drug Mafias. United States: Senate Foreign Relations Committee, Subcommittee on Western Hemisphere, Peace Corps, Narcotics, and Terrorism; 1997

22. Bewley-Taylor D. Challenging the UN drug control conventions: problems and possibilities. Int J Drug Policy. 2003;14(2):171-179.

23. Gomez G. Presencia de Consumo de Sustancias Psicoactivas en Pacientes que Acuden a Centros de Urgencias de dos Hospitales de Bogotá. Bogotá: Organizacion de Estados Americanos (OEA); 2004

24. Bejarano M. and Rendón LF. Injuries from external causes in minors (less than 18 years of age) and adults at a hospital in Colombia. Rev Panam Salud Publica. 2009;25(3):234-41.
25. NILMFS. FORENSIS. Bogota: National Institute of Legal Medicine and Forensic Sciences; 2013 Available at http:// www.medicinalegal.gov.co/forensis.

26. UNODC. The Globalization of Crime: A Transnational Organized Crime Threat Assessment. Vienna A: United Nations Office on Drugs and Crime; 2010.

27. Puyana JC, Puyana JC, Rubiano AM, Montenegro JH, Estebanez GO, Sanchez AI, Vega-Rivera F. Drugs, Violence and Trauma in México and the United States. Med Princ Pract. 2017 Mar 21. doi: 10.1159/000471853.

28. Rubiano AM, Sánchez AI, Guyette F and Puyana JC. Trauma care training for National Police nurses in Colombia. Prehosp Emerg Care. 2010;14(1):124-130. 